\title{
ACE-Inhibitors in High Vascular Risk: From Experimental Medicine to Clinical Trials
}

Fabio Angeli ${ }^{1^{*}}$, Gianpaolo Reboldi ${ }^{2}$, Cristina Poltronieri ${ }^{1}$ and Paolo Verdecchia ${ }^{3}$

${ }^{1}$ Division of Cardiology, Teaching Hospital S.M. della Misericordia, Perugia, Italy

${ }^{2}$ Department of Internal Medicine, University of Perugia, Perugia, Italy

${ }^{3}$ Department of Internal Medicine, Hospital of Assisi, Assisi, Italy

The Renin-Angiotensin System (RAS) is a complex regulatory system with many identifiable actions. It may primarily be viewed as a powerful regulatory system for the conservation of salt, blood volume and Blood Pressure (BP) [1]. However, an increased activity of the RAS, especially in combination with other cardiovascular (CV) risk factors, may lead to a cascade of deleterious effects.

Many of these pathophysiological actions is played by Angiotensin II (Figure 1, left panel) which stimulates atherosclerosis by triggering basic reactions leading to growth, inflammation, instability and rupture of atherosclerotic plaques, facilitation of thrombosis, and ultimately increasing the risk of major vascular events [1].

Furthermore, in the presence of conditions predisposing to hypertrophy, hyperplasia, and tissue remodeling, such as hypertension, atherosclerosis, diabetes, and others, even a normal activity of the RAS may result in inadequately elevated and may thus cause a further progression of the disease $[2,3]$.

Epidemiologic observational studies performed by measuring the levels of activity of the system support the concept that an enhanced activity of the RAS may be associated with higher risk of CV accidents. Further extensive evidence supporting this pathogenetic role of the RAS derives also from studies performed in high-risk populations $[4,5]$. In this context, inhibition of the RAS with angiotensin-converting enzyme inhibitors (ACE-Is) has been shown to lower BP effectively, and to attenuate the deleterious effects of Angiotensin II [1].

ACE-Is competitively block the action of ACE and thus the conversion of Angiotensin I to Angiotensin II, thereby reducing circulating and local levels of Angiotensin II [1]. This mechanism translates into beneficial actions in the processes of ventricular hypertrophy in hypertension, or vascular hypertrophy or hyperplasia in atherosclerosis and hypertension, or cardiac remodeling in Heart Failure (HF), or structural and functional abnormalities in the kidney in chronic renal failure [5-7].

In addition, the benefits of ACE-Is as standard treatment for high-risk patients with vascular disease and initially free of congestive HF have been proved beyond any reasonable doubt by some clinical trials [8]. The first of these studies, the Heart Outcomes Protection Evaluation (HOPE) trial [9], clearly demonstrated a beneficial effect of ACE-Is in patients at high risk of vascular disease because of Coronary Artery Disease (CAD), previous stroke, peripheral arterial disease or complicated diabetes. In these patients, ramipril significantly prevented $\mathrm{CV}$ death, stroke, Myocardial Infarction (MI), HF and diabetic micro vascular complications including nephropathy. In addition, it reduced the need for angioplasty and bypass surgery [9].

Similarly, the European Trial on Reduction of Cardiac Events with Perindopril in Stable Coronary Artery Disease (EUROPA) [10] analyzed the prognostic impact of perindopril in over 10,000 patients with CAD. It showed that the addition of the ACE-I perindopril to standard therapy significantly reduced the composite end point of $\mathrm{CV}$ death, MI, and cardiac arrest [10].

In the Survival and Ventricular Enlargement (SAVE) [11] and Studies of Left Ventricular Dysfunction (SOLVD) [12,13] trials, the long-term administration of ACE-Is therapy in MI patients with HF was associated with a significant reduction in the incidence of mortality and morbidity from CV events.

Conversely, in the Prevention of Events with Angiotensin Converting Enzyme Inhibition (PEACE) trial [14], the addition of trandolapril to standard therapy failed to provide any benefit in terms of death from CV causes, MI, or coronary revascularization (primary end-point). None of the examined subgroups had benefit from ACE-I therapy. This trial targeted patients with known CAD and ejection fraction equal to or greater than $40 \%$ and it was specifically conceived to extend to a lower risk population the observations emerged in the HOPE [9] study. Since a large proportion $(>60 \%)$ of patients in the PEACE trial [14] were concomitantly treated with modern lipidlowering, antiplatelet drugs and beta-blockers, it has been suggested that ACE-Is may fail to provide additional protection on top of modern CV preventive strategy.

Although conflicting results were generated exploring the impact of ACE inhibition therapy in CAD patients without HF [14,15], some recent meta-analyses suggested that ACE-Is should continue to be used in all patients with features of high vascular risk, even in a context of modern and intensive preventive strategies [4,15-17]. In this context, a pooled analysis of clinical trials from our group investigated the benefit of ACE-Is in patients at high vascular risk [4].

We used a relative (relative risk, $\mathrm{RR}$ ) and an absolute effect measure (risk difference) for the evaluation of the benefit associated to ACE-Is. We calculated RRs and 95\% confidence intervals (CIs) for all-cause death for each trial separately and for combination of studies according to random-effects model. A stratified analysis was also conducted for (a) trials which enrolled patients with vascular disease and HF and (b) trials which enrolled patients with vascular disease who did not have overt HF.

Overall, treatment with ACE-I's was associated with a significantly lower risk of all-cause mortality (RR 0.87, 95\% CI: 0.83-0.91,

*Corresponding author: Fabio Angeli, Division of Cardiology, Teaching Hospital S.M. della Misericordia, Perugia, Italy, Tel: +39-075-5782394 ; Fax: +39-075-5271509; E-mail: fangeli@cardionet.it

Received August 29, 2013; Accepted August 29, 2013; Published September 04, 2013

Citation: Angeli F, Reboldi G, Poltronieri C Verdecchia P (2013) ACE-Inhibitors in High Vascular Risk: From Experimental Medicine to Clinical Trials. Cardiol Pharmacol 2: e117. doi:10.4172/2329-6607.1000e117

Copyright: ( $) 2013$ Angeli F. et al. This is an open-access article distributed under the terms of the Creative Commons Attribution License, which permits unrestricted use, distribution, and reproduction in any medium, provided the original author and source are credited. 
Citation: Angeli F, Reboldi G, Poltronieri C Verdecchia P (2013) ACE-Inhibitors in High Vascular Risk: From Experimental Medicine to Clinical Trials. Cardiol Pharmacol 2: e117. doi:10.4172/2329-6607.1000e117

Page 2 of 3

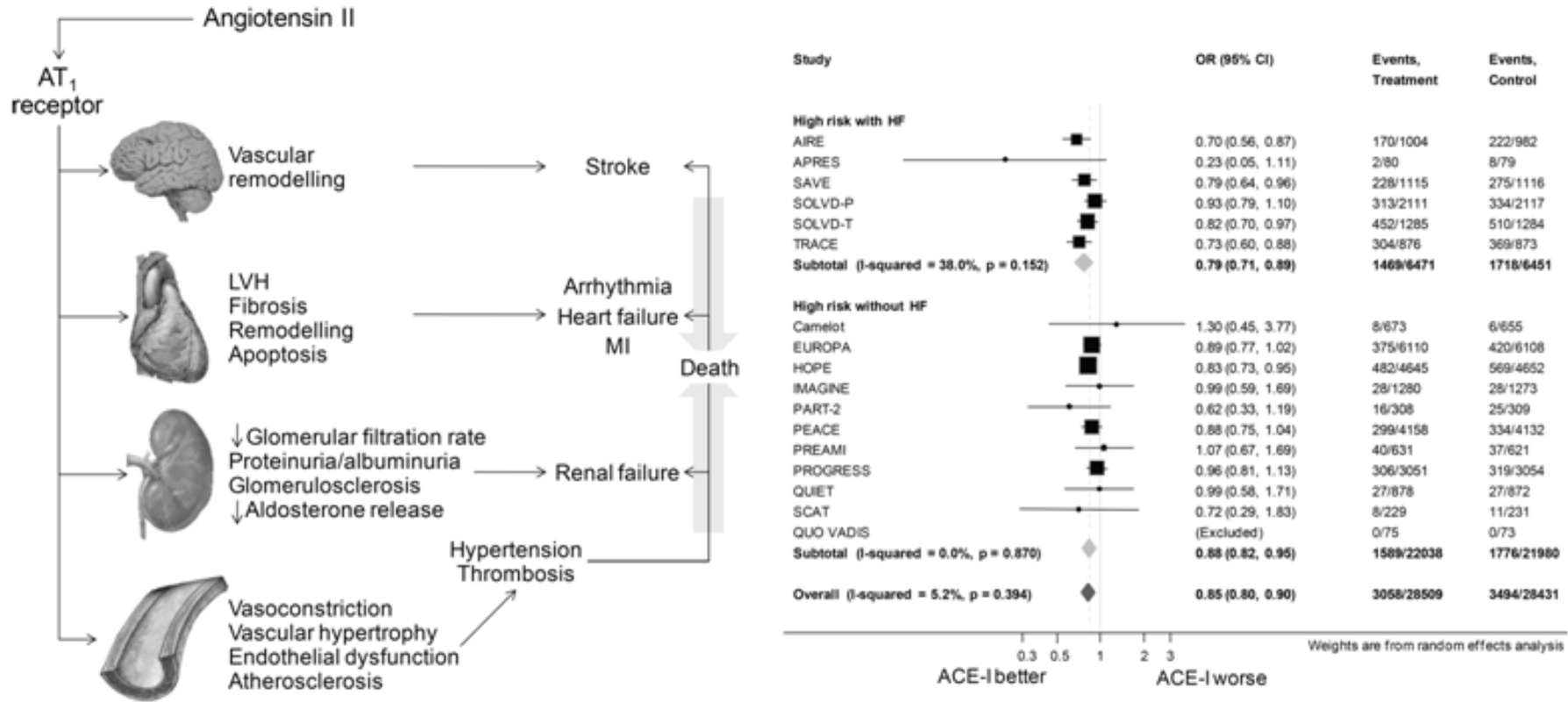

Abbreviations: $\mathrm{LVH}=$ left ventricular hypertrophy; $\mathrm{Ml}=$ myocardial infarction; $\mathrm{AT}=$ =angiotensin; $\mathrm{Cl}=$ confidence interval; $\mathrm{HF}=$ heart failure; $\mathrm{APRES}=\mathrm{Angiotensin}-\mathrm{converting}$ Enzyme Inhibition Post Revascularization Study; CAMELOT=Comparison of Amlodipine vs Enalapril to Limit Occurrences of Thrombosis; EUROPA=EURopean trial On reduction of cardiac events with Perindopril in stable coronary Artery disease; HOPE=Heart Outcomes Prevention Evaluation; IMAGINE=Ischemia Management with Accupril post bypass Graft via Inhibition of the converting Enzyme; PART-2=Prevention of Atherosclerosis with Ramipril Trila; PEACE=Prevention of Events with Angiotensin Converting Enzyme inhibition; PREAMI=Perindopril and remodeling in Elderly with Acute Myocardial Infarction; PROGRESS=Perindopril pROtection aGainst Recurrent Stroke Study; QUIET=Quinapril Ischemic Event Trial; QUO VADIS=Quinapril On Vascular ACE and Determinants of Ischemia; SAVE=Survival and Ventricular Enlargement; SCAT=Simvastatin/Enalapril Coronary Atherosclerosis Trial; SOLVD=Studies of Left Ventricular Dysfunction; TRACE=Trandolapril Cardiac Evaluation.

Figure 1: Biological actions of Angiotensin II and its role in vascular disease (left panel). Effect of treatment on all-cause mortality in trials comparing ACE-Is with placebo is also depicted (right panel). Solid squares represent the ORs in individual trials. Bars and diamond denote the $95 \%$ confidence intervals for individual trials and pooled estimates, respectively.

$\mathrm{p}<0.0001)$ compared to placebo and there was no evidence of statistical heterogeneity among the trials. Notably, ACE-Is were associated with a significant benefit in both patients with and without overt HF. In terms of absolute risk difference, ACE-Is showed a significant $4 \%$ reduction in all-cause mortality $(\mathrm{p}<0.0010)$ and $1 \%(\mathrm{p}=0.014)$ in patients with or without HF, respectively.

Similar results are obtained using odds ratio $(\mathrm{OR})$ as affect measure. Figure 1 (right panel) depicts the risk for all-cause death for each trial separately and for combination of studies. Overall, the use of ACE-Is confers a significant risk reduction of $15 \%$ (OR 0.85, 95\% CI: 0.80-0.90; $\mathrm{p}<0.0001)$. This effect was consistent in the two subgroups of clinical trials defined by the absence (OR 0.88, 95\% CI: 0.82-0.95; $\mathrm{p}=0.001$ ) or presence (OR $0.79,95 \%$ CI: $0.71-0.89$; p <0.0001) of overt HF at baseline. Notably, no heterogeneity was noted across trials $\left(\mathrm{I}^{2}=5.2 \%\right.$, $\mathrm{p}=0.394)$.

In conclusion, the RAS is an important contributor to the pathogenesis of $\mathrm{CV}$ disease and its modulation by ACE-Is improve outcomes in some conditions including hypertension, diabetes and atherosclerotic disease [5,18]. Moreover, available evidences from experimental models and clinical trials strongly suggest that ACE-Is should continue to be largely used in all patients with features of high vascular risk with or without left ventricular systolic dysfunction [4].

\section{References}

1. Jacoby DS, Rader DJ (2003) Renin-angiotensin system and atherothrombotic disease: from genes to treatment. Arch Intern Med 163: 1155-1164.
2. Hall JE, Granger JP, Hester RL, Coleman TG, Smith MJ Jr, et al. (1984) Mechanisms of escape from sodium retention during angiotensin II hypertension. Am J Physiol 246: F627-634.

3. Khalil ME, Basher AW, Brown EJ Jr, Alhaddad IA (2001) A remarkable medical story: benefits of angiotensin-converting enzyme inhibitors in cardiac patients. J Am Coll Cardiol 37: 1757-1764.

4. Angeli F, Reboldi G, Verdecchia P (2011) Modern treatment of patients at risk: still a HOPE for ACE inhibitors? Expert Opin Pharmacother 12: 839-843.

5. Reboldi G, Gentile G, Angeli F, Verdecchia P (2009) Choice of ACE inhibitor combinations in hypertensive patients with type 2 diabetes: update after recent clinical trials. Vasc Health Risk Manag 5: 411-427.

6. Wolny A, Clozel JP, Rein J, Mory P, Vogt P, et al. (1997) Functional and biochemical analysis of angiotensin II-forming pathways in the human heart. Circ Res 80: 219-227.

7. Angeli F, Verdecchia P, Reboldi GP, Gattobigio R, Bentivoglio M, et al. (2004) Meta-Analysis of effectiveness or lack thereof of angiotensin-converting enzyme inhibitors for prevention of heart failure in patients with systemic hypertension. Am J Cardiol 93: 240-243.

8. Reboldi G, Angeli F, Cavallini C, Gentile G, Mancia G, et al. (2008) Comparison between angiotensin-converting enzyme inhibitors and angiotensin receptor blockers on the risk of myocardial infarction, stroke and death: a meta-analysis. J Hypertens 26: 1282-1289.

9. Yusuf S, Sleight P, Pogue J, Bosch J, Davies R, et al. (2000) Effects of an angiotensin-converting-enzyme inhibitor, ramipril, on cardiovascular events in high-risk patients. The Heart Outcomes Prevention Evaluation Study Investigators. N Engl J Med 342: 145-153.

10. Fox KM; EURopean trial On reduction of cardiac events with Perindopril in stable coronary Artery disease Investigators (2003) Efficacy of perindopril in reduction of cardiovascular events among patients with stable coronary artery 
Citation: Angeli F, Reboldi G, Poltronieri C Verdecchia P (2013) ACE-Inhibitors in High Vascular Risk: From Experimental Medicine to Clinical Trials. Cardiol Pharmacol 2: e117. doi:10.4172/2329-6607.1000e117

disease: randomised, double-blind, placebo-controlled, multicentre trial (the EUROPA study). Lancet 362: 782-788.

11. Pfeffer MA, Braunwald E, Moye LA, Basta L, Brown EJ Jr, et al. (1992) Effect of captopril on mortality and morbidity in patients with left ventricular dysfunction after myocardial infarction. Results of the survival and ventricular enlargement trial. The SAVE Investigators. N Engl J Med 327: 669-677.

12. The SOLVD Investigators (1991) Effect of enalapril on survival in patients with reduced left ventricular ejection fractions and congestive heart failure. The SOLVD Investigators. N Engl J Med 325: 293-302.

13. The SOLVD Investigators (1992) Effect of enalapril on mortality and the development of heart failure in asymptomatic patients with reduced left ventricular ejection fractions. The SOLVD Investigattors. N Engl J Med 327: $685-691$.

14. Braunwald E, Domanski MJ, Fowler SE, Geller NL, Gersh BJ, et al. (2004) Angiotensin-converting-enzyme inhibition in stable coronary artery disease. $\mathrm{N}$ Engl J Med 351: 2058-2068.
15. Danchin N, Cucherat M, Thuillez C, Durand E, Kadri Z, et al. (2006) Angiotensinconverting enzyme inhibitors in patients with coronary artery disease and absence of heart failure or left ventricular systolic dysfunction: an overview of long-term randomized controlled trials. Arch Intern Med 166: 787-796.

16. Flather MD, Yusuf S, Køber L, Pfeffer M, Hall A, et al. (2000) Long-term ACEinhibitor therapy in patients with heart failure or left-ventricular dysfunction: a systematic overview of data from individual patients. ACE-Inhibitor Myocardial Infarction Collaborative Group. Lancet 355: 1575-1581.

17. Verdecchia P, Angeli F, Cavallini C, Gattobigio R, Gentile G, et al. (2009) Blood pressure reduction and renin-angiotensin system inhibition for prevention of congestive heart failure: a meta-analysis. Eur Heart J 30: 679-688.

18. Verdecchia P, Angeli F (2003) The Seventh Report of the Joint Nationa Committee on the Prevention, Detection, Evaluation and Treatment of High Blood Pressure: the weapons are ready. Rev Esp Cardiol 56: 843-847. 